\title{
EFEITO INIBIDOR DO CRESCIMENTO TUMORAL PELA METIONINA-ENCEFALINA
}

GEORGIA MASCARENHAS* - THEREZA QUIRICO-SANTOS *

RESUMO - A metionina-enceflalina (Met-Enk) e um pentapeptídeo opióide derivado do pró-normônio proencefalina A, presente em células neuroendócrinas e hematopoéticas. Estudos experimentais evidenciam seu papel na indução, ativação e controle de eventos imunomoduladores, inclusive com potente efeito inibidor do crescimento tumoral. o presente estudo demonstra que o efeito inibidor da Met-Enk no crescimento de um fibro-histiocitoma, em camundongos BALB/cJ, é influenciado pelo protocolo utilizado, via de administração e dose do pentapeptídeo opióide utilizada no tratamento. A administração de Met_Enk por via intracerebral retardou de forma eficiente o processo de tumorigênese, aumentando a sobrevida dos animais e reduzindo de forma significativa a área tumoral final. Dose baixa $(0,25 \mathrm{mg} / \mathrm{kg})$ de Met-Enk administrada por via intracerebral foi ainda mais potente no controle da tumorigênese.

PALAVRAS CHAVE: histiocitoma, metionina-encefalina, neuroimunomodulação.

Inhibitory effect of methionine-enkephalin on tumor growth.

SUMMARY - Methionine-enkephalin (Met_Enk) is an endogenous opioid pentapeptide derived from the prohormone proenkephalin A, present in neuroendocrine and hematopoietic cells. Enkephalins are known to play an important role on the processes of induction, activation and control of immunomodulatory events. Met-Enk has been considered a potent antitumoral agent. The present study shows that Met-Enk exerts an inhibitory effect on the growth of a macrophage derived fibrous histiocytoma (MC-II) inoculated intradermally into BALB/cJ mice. Such effect was mainly influenced by the protocol, route of administration and concentration of Met_Enk used for treatment. Neither higher doses of Met-Enk injected intracerebrally or subcutaneously, nor the use of various protocols of treatment, did modify the process of tumorigenesis. In contrast, low dose $(0.25 \mathrm{mg} / \mathrm{kg})$ of Met-Enk injected intracerebrally together with tumor inoculation, significantly reduced tumor growth and prolonged survival rate.

KEY WORDS: histiocytoma, methionine-enkephalin, neuroimmunemodulation.

Evidências experimentais $5,8,13$ indicam que peptídeos endógenos neuroendócrinos, incluindo peptídeos opiódes, modulam a imunidade celular e humoral. A existência de receptores opióides de alta e baixa afinidade tem sido observada em leucócitos, células acessórias, plaquetas e componentes do sistema complemento 7,9,12. Metionina-encefalina (Met-Enk) é um pentapeptideo opióide derivado do pró-hormônio proencefalina $A$, presente em células neuroendócrinas e hematopoéticas 15,16. A utilização em sistemas in vitro de substâncias agonistas e antagonistas dos receptores opióides indica a existência de uma ligação clássica de interação da Met-Enk preferencialmente a receptores delta porém, de acordo com sua concentração, é possível a ligação a receptores kappa e mu11. Recentemente 16, em estudos utilizando cultura de células tumorais S20Y de neuroblastoma, foi possível a identificação de novo tipo (zeta) de receptor opióide, ao qual a Met-Enk também exibe alta afinidade. Este receptor está provavelmente envolvido no controle da proliferação celular 14,16. A expressão de várias classes de receptores opióides pode ser evidenciada em diversas linhagens tumorais 10,17, sendo observada potente ação anti-tumoral das encefalinas sobre células

* Laboratório de Imunologia Celular, Departamento de Patologia, Hospital Universitário Antonio Pedro, Universidade Federal Fluminense (UFF).

Dra. Thereza Quirico-Santos - Hospital Universitario Antonio Pedro, Departamento de Patologia - Rua Marques do Paraná 303 - 24230 Niterbi RJ - Brasil. 
do melanoma B16 4,16, leucemia L12101 e neuroblastoma de murinos 4 . A expressão, pela mesma célula, de diferentes tipos de receptores opiódes, tem sido observada em linhagens tumorais de macrófagos (P388d1), linfófitos B (IM-9) e linfócitos T $(\text { MOLT }-4)^{2}$.

Este estudo teve por objetivo observar em camundongos BALB/cJ o efeito do tratamento da metionina-encefalina no crescimento in vivo do fibro-histiocitoma MC-II, um tumor com características citoquímicas e funcionais da linhagem macrofágica.

\section{MATERIAL E METODOS}

Animais - Forram utilizados camundongos BALB/cJ, macho, com 12-16 semanas de idade provenientes do biotério de murideos do Departamento de Patologia da UFF. Antes de serem utilizados, no mínimo 6 animais por grupo, o dorso foi depilado com tosquiadeira eletrica, sendo injetadas por via intradérmica 16 células viáveis da suspensão tumoral.

Tumor - O tumor MC-II, inicialmente induzido em camundongos B10A pela administração do metil_colantreno, utilizando o modelo bifásico de carcinogênese química cutânea, foì mantido por sucessivas passlagens intraperitoneais e subcutâneas em camundongos BALB/cJ. $O$ tumor foi classificado segundo critérios histomorfológicos como fibro-histiocitoma e, por estudos citoquímicos e funcionais, como pertencendo à linhagem macrofágica. $O$ tumor expressa antígenos (Ia) da classe II do MHC, sendo também identificado pelo anticorpo monoclonal Mac-1. Células viáveis (um milhão) foram injetadas por via intradérmica no dorso de camundongos BALB/cJ, sendo este considerado como dia 0. Três vezes por semana a medida do crescimento tumoral foi avaliada com auxílio de paquímetro, obtendo-se sempre duas medidas perpenåiculares sendo estabelecida, para cada animal, curva de crescimento tumoral. $O$ cálculo da replicação tumoral e do tempo de duplicação do tumor foi obtido de acordo com Steel (1982). Os resultados foram analisados usando análise de variância (two-way ANOVA test).

Tratamento com metionina_encefalina - A metionina-encefalina acetato (Sigma Chem. Co., USA) foi dissolvida em água destilada e esterilizada por filtração em membrana Millipore de poro 0,22u. Camundongos $B A L B / c J$, distribuidos em grupos de 6, receberam por via subcutânea (s.c.) $2,5 \mathrm{mg} / \mathrm{kg}$ de Met-Enk semanalmente, após o aparecimento do nódulo tumoral, 24 horas antes e 7 dias após $(-1+7)$ a inoculação do tumor ou 24 horas e 7 dias após $(+1+7)$ a inoculação de um milhão de células tumorais viáveis. Met-Enik também foi administrada por via intracerebral (i.c.) via forame esfenoglenóide, nas seguintes concentrações: $0,25 \mathrm{mg} / \mathrm{kg}$, $2,5 \mathrm{mg} / \mathrm{kg}$ e $5,0 \mathrm{mg} / \mathrm{kg}$. Os experimentos foram realizados um mínimo de três vezes. Os animais dos grupos controle, receberam salina estéril por via subcutânea ou por via intracerebral.

\section{RESULTADOS}

Todos os animais do grupo controle, recebendo ${ }_{6}$ salina por via subcutânea ou intracereural e inoculados por via intradérmica com $10^{6}$ células do fribo_histiocitoma, apresentaram periodos de implantação e padrão de crescimento tumoral similares.

O tratamento dos animais (Fig. 1) com $2,5 \mathrm{mg} / \mathrm{kg}$ de Met-Enk por via s.c. uma vez no momento da inoculação do tumor ou semanalmente não alterou, em comparação ao grupo controle recebendo salina s.c., a curva de crescimento tumoral nem reduziu de forma significativa (Tabela 1) a massa tumoral final. A mesma dose de Met-Enk administrada por via

Tabela 1 - Medida do crescimento tumoral.

\begin{tabular}{cccccc}
\hline Dias & Controle & Semanal & Dia 0 & Pos-nódulo & Intracerebral \\
\hline 9 & $85 \pm 19$ & $78 \pm 22$ & $80 \pm 10$ & $69 \pm 12$ & $74 \pm 17$ \\
15 & $181 \pm 45$ & $175 \pm 29$ & $177 \pm 40$ & $147 \pm 46$ & $147 \pm 20$ \\
21 & $200 \pm 54$ & $195 \pm 40$ & $231 \pm 56$ & $183 \pm 63$ & $165 \pm 18$ \\
27 & $325 \pm 41$ & $293 \pm 72$ & $309 \pm 53$ & $267 \pm 98$ & $229 \pm 45$ \\
\hline
\end{tabular}

Grupos de 6 camundongos BALB/cJ foram tratados com 2,5mg/kg Met-Enk por via intracerebral ou por via subcutanea semanalmente, após tumoraçáo ou no dia da inoculaçáa de $10^{6}$ células viaveis do tumor MC-II por via intradermica. 

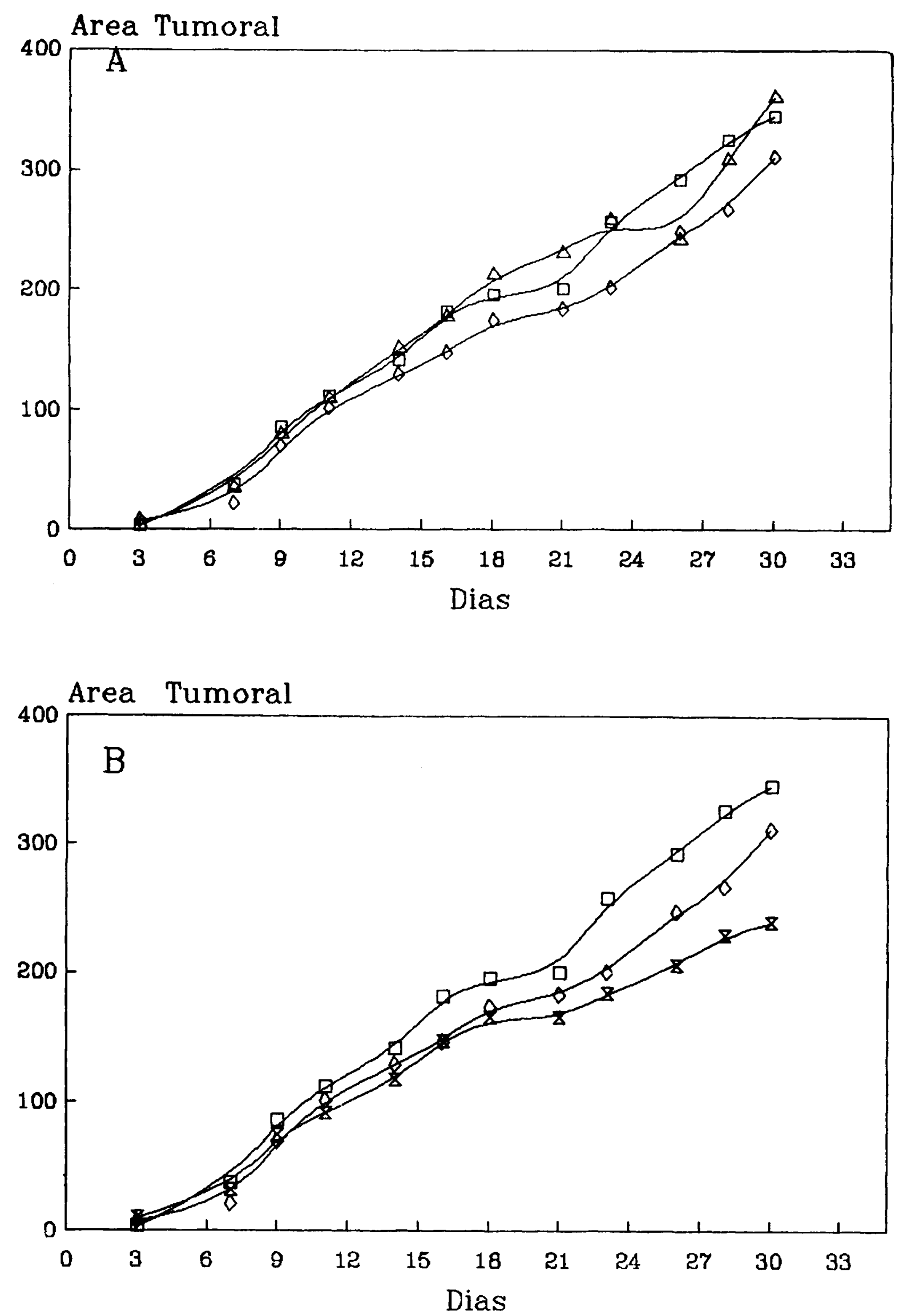

Fig. 1 - (A) Grupos de 6 camundongos BALB/CJ foram tratados com 2,5mg/kg de Met-Enk por via subcutanea após tumoração ( $\diamond)$ ou no dia 0 ( $\square$ ) da inoculação de $10^{6}$ células do tumor MC-II por via intradermica. (B) Grupos de 6 camundongos BALB/CJ foram tratados com 2,5mg/kg de Met-Enk por via intracerebral ( $Z$ ) ou por via subcutanea semanalmente ( $\diamond$ ). 0 grupo controle $(\Delta)$ recebeu salina estéril por via subcutanea. 

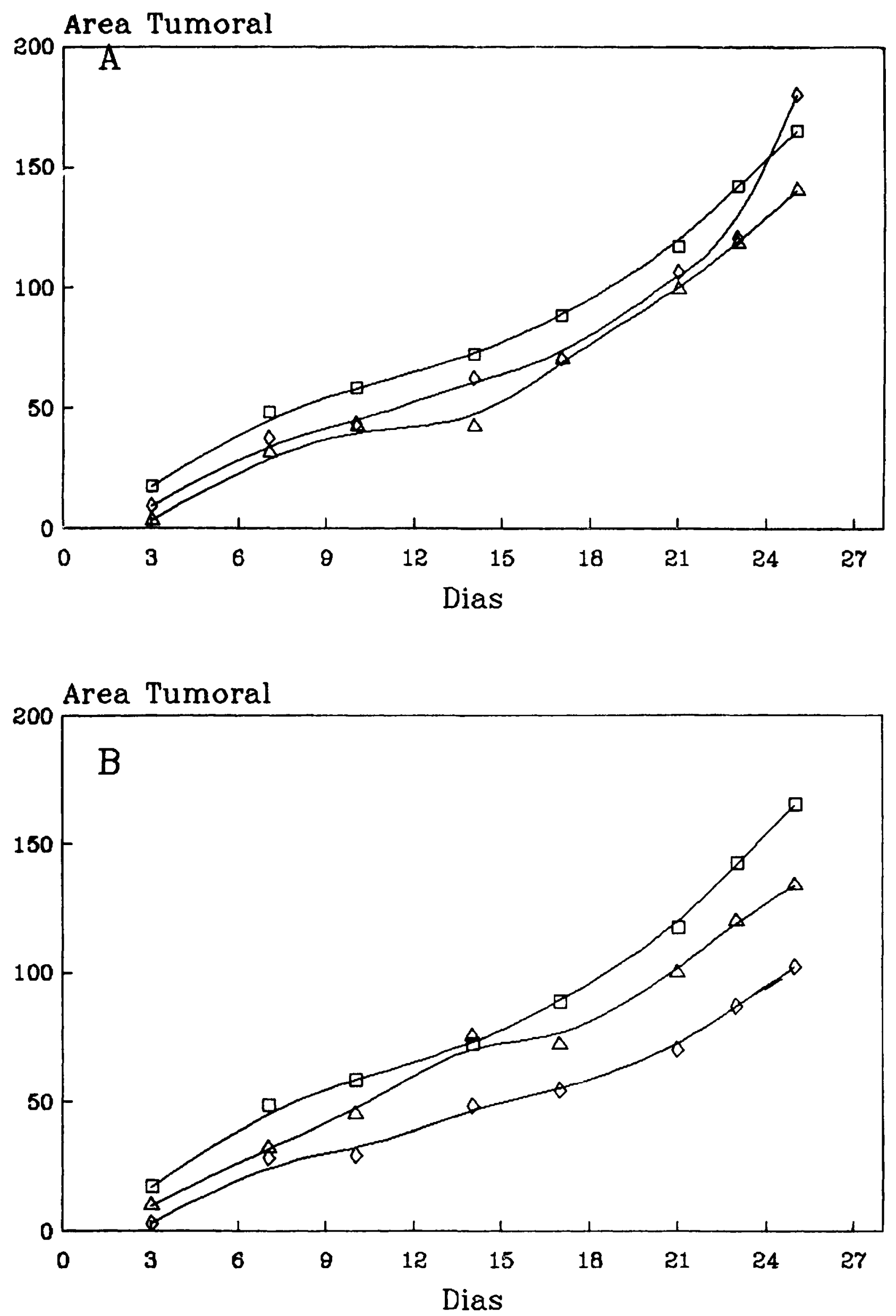

Fig. 2 - (A) Grupos de 6 camundongos $B A L B / C J$ foram inoculados com $10^{6}$ células vidveis do tumor MC-II por via intradermica: $2,5 \mathrm{mg} / \mathrm{kg}$ de Met-Enk foram administrados por via subcutanea nos dias $+1+7(\Delta)$ ou por via intracerebral $(\diamond)$ na dose $5,0 \mathrm{mg} / \mathrm{kg}$ (dose alta) no mesmo dia da inoculação do tumor. (B) Grupos de 6 camundongos BALB/cJ foram tratados com 2,5mg/kg de Met-Enk por via subcutanea nos dias $-1+7(\Delta)$ ou por via intracercbral ( $)$ na dose $0,25 \mathrm{mg} / \mathrm{kg}$ (dose baixa) no mesmo dia da inoculaşäo do tumor. o grupo controle (口) recebeu salina por via subcutanea. 
s.c., quando a tumoração atingiu área de $4 \mathrm{~mm} 2$ (Fig. 1a). diminuiu o crescimento tumoral sem alterar o tempo de duplicação tumoral. Em consequência não se observou, comparando-se ao grupo controle não tratado, redự̧ão significativa $(p<0,1)$ da área final do tumor. Por outro lado (Tabela 1), o tratamento com $2.5 \mathrm{mg} / \mathrm{kg}$ de Met-Eink por via i.c., embora não alterando o padrão da curva de crescimento tumoral (Fig. 1b), retardou o processo de tumo_ rigênese, causando redução significativa $(\mathrm{p}<0,01)$ da massa tumoral final.

A administração de $2,5 \mathrm{mg} / \mathrm{kg}$ de Met-Enk por via s.c. (Tabela 2) 24 horas antes e 7 dias após $(-1+7)$ a inoculação do tumor, apesar de retardar o período de implantação do tumor, não alterou o padrão da curva de crescimento tumoral. o tratamento de Met-Enk por via s.c. 24 horas e 7 dias após $(+1+7)$ a inoculação das células do MC-II causou redução discreta porém não significativa $(\mathrm{p}<0,1)$ da massa tumoral final.

Dose alta $(5,0 \mathrm{mg} / \mathrm{kg})$ de Met-Enk por via i.c (Tabela 2) causou inicialmente progressão rápida do crescimento tumoral, não sẹ observando redução da massa tumoral final, ao final do experimento. No entretanto, o tratamento com dose baixa $(0,25 \mathrm{mg} / \mathrm{kg})$ de Met-Enk (Tabela 2) por via i.c. foi o que obteve maior exito em inibir o crescimento tumoral, aumen. tando significativamente $(p<0,01)$ a sobrevida dos animais. O padrão da curva de crescimento do tumor (Fig. 2b) nos camundongos deste grupo manteve-se sempre bem abaixo dos demais grupos tratados e sua massa tumoral final foi significativamente $(p<0,01)$ menor que a do grupo controle não tratado.

Tabela 2 - Medida do crescimento tumoral.

\begin{tabular}{|c|c|c|c|c|c|}
\hline \multirow[b]{2}{*}{ Dias } & \multirow[b]{2}{*}{ Controle } & \multicolumn{2}{|c|}{ Via subcutânea } & \multicolumn{2}{|c|}{ Via intracerebral } \\
\hline & & $-1+7$ & $+1+7$ & Dose alta & Dose baixa \\
\hline 9 & $58 \pm 9$ & $45 \pm 12$ & $42 \pm 22$ & $43 \pm 20$ & $29 \pm 14$ \\
\hline 15 & $72 \pm 15$ & $75 \pm 13$ & $42 \pm 22$ & $62 \pm 18$ & $48 \pm 10$ \\
\hline 21 & 117 土 33 & $100 \pm 22$ & $99 \pm 36$ & $106 \pm 30$ & $70 \pm 21$ \\
\hline 24 & $165 \pm 46$ & $134 \pm 30$ & $140 \pm 51$ & $180 \pm 40$ & $102 \pm 38$ \\
\hline
\end{tabular}

Grupos de 6 camundongos BALB/cJ foram inoculados com $10^{6}$ células viáveis do tumor MC-II por via intradermica: $0,5 \mathrm{mg} / \mathrm{kg}$ de Met-Enk foi auministrado por via subcutanea nos dias $-1+7$ ou $+1+7$ e por via intracerebral nas doses $0,25 \mathrm{mg} / \mathrm{kg}$ (dose baixa) ou $5,0 \mathrm{mg} / \mathrm{kg}$ (dose alta) no mesmo dia da inoculacão do tumor.

\section{COMENTARIOS}

Eventos carcinogênicos associados a neoplasias humana e animal podem ser modulados, in vivo e in vitro, por substâncias agonistas e antagonistas opiódes 16. Os neuro-hormônios opióides exercem vários efeitos sobre processos imunológicos, incluindo: aumento na percentagem de linfócitos $\mathrm{T}$ com atividade formadora de rosetas 15, na estimulação in vitro da blastogênese de linfócitos humanos e murinos, no aumento da atividade de células NK ${ }^{17}$. Metionina-encefalina, um neuro-hormônio opióide produzido por células neuroendócrinas e hematopoéticas 15 , tem sido recentemente 17 incluído no grupo dos polipeptídeos inibidores do crescimento celular junto com fator de crescimento tumoral (TNF), interferon e chalonas. A metionina-encefalina atua diretamente em receptores delta, mu, kappa ou zeta, presentes em células normais e neoplásicas, modulando a proliferação celular.

Nos experimentos realizados com MC-II, um fibro-histiocitoma apresentando marcadores celulares da linhagem macrofágica, observaram-se curvas de crescimento tumoral semelhantes entre o grupo controle e aqueles recebendo Met-Enk também por via s.c. após o aparecimento do nódulo. O tratamento entretanto causou, no final do experimento, área tumoral menor apesar de, nos três primeiros dias, ter acelerado o crescimento tumoral.

Met-Enk administrada i.c. ou por via s.c. semanalmente e após o aparecimento do nódulo causou crescimento tumoral menor que aquele do grupo controle. O tratamento com dose baixa $(0,25 \mathrm{mg} / \mathrm{kg})$ de Met-Enk por via intracerebral foi o mais eficiente em controlar $o$ crescimento tumoral, diminuindo significativamente $(p<0,01)$ a 
massa tumoral e aumentando a sobrevida dos animais. Esses resultados estão de acordo com os experimentos de Jankovic e Maric 4 que afirmam ser a via intracerebral a mais indicada para a administração de peptídeos opióides, sendo sugerido que por esta via o efeito modulador central do pentapeptídeo opióide seria intenso e de ação prolongada, em decorrência da ligação direta aos receptores específicos presentes no sistema nervoso central (SNC) e à baixa velocidade de dissociação do seu receptor. As doses de Met-Enk mais eficazes na inibição do crescimento tumoral foram as mais baixas. Tem sido sugerido 4 que doses baixas de Met-Enk causam imunoestimulação enquanto doses altas, imunosupressão. A observação de que a admínistração por via i.c. foi a mais eficiente em controlar o processo de tumorigênese vem apoiar a hipótese 4 que sugere a existência de mecanismo central de imunomodulação, no controle da imunidade anti-tumoral. provavelmente associado à interação neuropeptídeos-receptores. Os neuropeptídeos atuariam tanto a nivel de receptores específicos presentes no SNC e nas células hematopoéticas, como também agiriam diretamente sobre as células NK aumentando a atividade citotóxica 8 .

As células NK participam na eliminação de células neoplásicas e infectadas por vírus e parasitas 1. Assim, fatores moduladores da atividade citotóxica destas células, incluindo os peptídeos opióides endógenos, poderiam ser capazes de influenciar o curso da tumorigênese por alterarem o crescimento de neoplasias inoculadas experimentalmente, particularmente na fase inicial do crescimento tumoral. Não se pode, entretanto, afastar a hipótese de que Met-Enk administrada por via subcutânea possa estar também exercendo ação direta sobre a célula tumoral. As células tumorais MC-II foram classificadas como sendo de origem macrofágica em virtude de fagocitarem leveduras, apresentarem reação citoquímica positiva para lisozima, alfa-naftil esterase e fosfatase ácida, além de serem reconhecidas pelo anticorpo monoclonal anti-Ia e anti-Macl e expressarem vimentina como principal componente do citoesqueleto. Recentemente 3,6 , a presença de receptores para opióides, foi também evidenciada nas células macrofágicas. No entanto, faz-se necessária a execução de experimentos adicionais, in vivo $e$ in vitro, que caracterizem e identifiquem os receptores para as encefalinas presentes nas células tumorais $\mathrm{MC}$-II, além de estudos que identifiquem os mecanismos prováveis (direto e/ou indireto) envolvidos, no controle da proliferação celular tumoral.

\section{REFERENCIAS}

1. Bernton E, Frondoza C, Grzanna R, Holaday J. Effects of naloxune on the growth of LPPC-1 plasmacytoma in mice. Proc First Internat Workshop on Neuroimmunomodulation. International Working Group on Neuroimmunomodulation (IWGN), Bethesda, 1985, p 245-248 (abstr).

2. Carr DJJ, De Costa BR, Kim C-H, Jacobson AE, Guarcello V, Rice KC, Blalock JE. Opioid receptors on cells of the immune system: evidence for delta and kappa-classes. $\mathrm{J}$ Endocrinol 1989, $122: 161-186$.

3. Deitch EA, Dazhong X, Bridges RMCI. Opioids modulate human neutrophil and lymphocyte function: thermal injury alters plasma beta-endorphin levels. Sugery 1988, 104: 41-48.

1. Jankovic B, Maric D. Enkephalins and immunity. II: In vivo modulation of cell-mediated immunity. Ann NY Acad Sci 1987, 496:126-136.

5. Jankovic B, Maric D. Enkephalins modulate in vivo immune reactions through deltá und mu opioid receptors. Ann NY Sci 1988, 540:691-693.

6. Lopker A, Abood LG, Hoss W, Lionetti F. Stereoselective muscarinic acetylcholine opiate receptors in human phagocytic leukocytes. Biochem Pharmacol 1980, 29:1361-1365.

7. Mehrishi JN, Mills IH. Opioid receptors on lymphocytes and platelets in man. Clin Immunol Immunopathol 1983, 27:240-249.

8. Morcos R, Seidah NG, Lazure C, Chretien M. Endorphines 1989: aspects neuroendocriniens. Rev Neurol (Paris) 1989, 145:747-753.

9. Ovadia H, Nitsan P, Abramsky O. Characterization of opioid binding sites on membranes of rat lymphocyte. J Neuroimmunol 1989, 21:193_202.

10. Plotnikoff NP, Faith RE, Murgo AJ, Miller GC. Enkephalins: immunomodulators and «antitumoral activities». Proc First Internat Workshop on Neuroimmunomodulation. International Working Group on Neuroimmunomodulation (IWGN), Bethesda, 1985, p 240-242 (abstr).

11. Plotnikoff NP. Opioids: immunomodulators. A proposed role in cancer and aging. Ann NY Acad Sci 1988, 521:312-322. 
12. Schweigerer L, Bhakdi S, Teschemacher H. Specific non-opioid binding sites for human beta-endorphin on the terminal complex of human complement. Nature 1982, 296:572-574.

13. Sibinge NES, Goldstein A. Opioid peptides and opioid receptors in cell of the immune system. Ann Rev Immunol 1988, 6:219_249.

14. Zagon IS, Goodman SR, McLaughlin PJ. Characterization of zeta: a new opioid receptor involved in growth. Brain Res 1989, 482:297-305.

15. Zagon IS, McLaughlin PJ. Modulation of murine neuroblastoma in nude mice by opioid antagonists. J Natl Cancer Inst 1987, 78:141-147.

16. Zagon IS, McLaughlin P. Endogenous opioids and the growth regulation of a neural tumor. Life Sci 1988, 43:1313-1318.

17. Zagon IS, McLaughlin PJ. Endogenous opioid systems regulate growth of neural tumor cells in culture. Brain Res 1989, 490:14-25.

18. Zagon IS, McLaughlin PJ, Goodman SR, Rhodes RE. Opioid receptors and endogenous opioids are present in diverse human animal cancers. J Natl Cancer Inst 1987, 79:1059-1065. 